\title{
Long-term observations minus background monitoring of ground-based brightness temperatures from a microwave radiometer network
}

\author{
Francesco De Angelis ${ }^{1}$, Domenico Cimini ${ }^{2,1}$, Ulrich Löhnert ${ }^{3}$, Olivier Caumont ${ }^{4}$, Alexander Haefele ${ }^{5}$, \\ Bernhard Pospichal $^{3}$, Pauline Martinet ${ }^{4}$, Francisco Navas-Guzmán ${ }^{6}$, Henk Klein-Baltink ${ }^{7}$, Jean-Charles Dupont ${ }^{8}$, \\ and James Hocking ${ }^{9}$ \\ ${ }^{1}$ CETEMPS, University of L'Aquila, L'Aquila, Italy \\ ${ }^{2}$ National Research Council of Italy, Institute of Methodologies for Environmental Analysis (IMAA-CNR), Potenza, Italy \\ ${ }^{3}$ Institute for geophysics and meteorology, University of Cologne, Cologne, Germany \\ ${ }^{4}$ CNRM UMR 3589, Météo-France/CNRS, Toulouse, France \\ ${ }^{5}$ Federal Office of Meteorology and Climatology MeteoSwiss, Payerne, Switzerland \\ ${ }^{6}$ Institute of Applied Physics (IAP), University of Bern, Bern, Switzerland \\ ${ }^{7}$ Royal Netherlands Meteorological Institute (KNMI), De Bilt, the Netherlands \\ ${ }^{8}$ Institut Pierre-Simon Laplace (IPSL), Université Versailles Saint Quentin, Guyancourt, France \\ ${ }^{9}$ Met Office, Exeter, UK
}

Correspondence to: F. De Angelis (francesco.deangelis1@graduate.univaq.it)

Received: 12 April 2017 - Discussion started: 21 April 2017

Revised: 25 August 2017 - Accepted: 15 September 2017 - Published: 25 October 2017

\begin{abstract}
Ground-based microwave radiometers (MWRs) offer the capability to provide continuous, high-temporalresolution observations of the atmospheric thermodynamic state in the planetary boundary layer (PBL) with low maintenance. This makes MWR an ideal instrument to supplement radiosonde and satellite observations when initializing numerical weather prediction (NWP) models through data assimilation. State-of-the-art data assimilation systems (e.g. variational schemes) require an accurate representation of the differences between model (background) and observations, which are then weighted by their respective errors to provide the best analysis of the true atmospheric state. In this perspective, one source of information is contained in the statistics of the differences between observations and their background counterparts (O-B). Monitoring of O-B statistics is crucial to detect and remove systematic errors coming from the measurements, the observation operator, and/or the NWP model. This work illustrates a 1-year O-B analysis for MWR observations in clear-sky conditions for an European-wide network of six MWRs. Observations include MWR brightness temperatures (TB) measured by the two most common types of MWR instruments. Background pro-
\end{abstract}

files are extracted from the French convective-scale model AROME-France before being converted into TB. The observation operator used to map atmospheric profiles into TB is the fast radiative transfer model RTTOV-gb. It is shown that O-B monitoring can effectively detect instrument malfunctions. O-B statistics (bias, standard deviation, and root mean square) for water vapour channels $(22.24-30.0 \mathrm{GHz})$ are quite consistent for all the instrumental sites, decreasing from the $22.24 \mathrm{GHz}$ line centre $(\sim 2-2.5 \mathrm{~K})$ towards the high-frequency wing $(\sim 0.8-1.3 \mathrm{~K})$. Statistics for zenith and lower-elevation observations show a similar trend, though values increase with increasing air mass. O-B statistics for temperature channels show different behaviour for relatively transparent $(51-53 \mathrm{GHz})$ and opaque channels $(54-58 \mathrm{GHz})$. Opaque channels show lower uncertainties $(<0.8-0.9 \mathrm{~K})$ and little variation with elevation angle. Transparent channels show larger biases $(\sim 2-3 \mathrm{~K})$ with relatively low standard deviations $(\sim 1-1.5 \mathrm{~K})$. The observations minus analysis TB statistics are similar to the $\mathrm{O}-\mathrm{B}$ statistics, suggesting a possible improvement to be expected by assimilating MWR TB into NWP models. Lastly, the O-B TB differences have been evaluated to verify the normal-distribution hypothesis under- 
lying variational and ensemble Kalman filter-based DA systems. Absolute values of excess kurtosis and skewness are generally within 1 and 0.5 , respectively, for all instrumental sites, demonstrating O-B normal distribution for most of the channels and elevations angles.

\section{Introduction}

The new generation of high-resolution $(\sim 1 \mathrm{~km}$ grid size $)$ weather forecast models now operational over Europe promises to improve predictions of high-impact weather, ranging from flash floods to episodes of poor air quality. To realize this, a dense observing network is required, focusing especially on the lowest few kilometres of the atmosphere, so that forecast models have the most realistic state of the atmosphere for initial states and subsequent forecasts. The United States National Research Council (NRC) recently reported that continuous planetary boundary layer (PBL) thermodynamic observations provide a practical and cost-effective means to improve local high-impact weather forecasting (National Research Council, 2008, 2010). However, they stated that the structure and variability of the lower troposphere is currently not well known because vertical profiles of water vapour, temperature, and winds are not systematically observed. This lack of observations results in the PBL being the single most important under-sampled part of the atmosphere. While the thermodynamic state of the atmosphere is well measured at the surface by in situ sensors (e.g. weather stations) and in the upper troposphere by satellite sounders, there is currently an observational gap in the PBL. Ground-based microwave radiometers (MWRs) offer the capability to provide continuous temperature and humidity profiles in both clear- and cloudy-sky conditions with high temporal resolution, low-to-moderate vertical resolution, and with information mostly residing in the PBL (Cimini et al., 2006). Thus, MWR can help bridging the current observational gap in this thin layer of the troposphere. More than 30 MWR are currently installed in Europe, most of which are operating continuously, and the number is increasing. In this framework, MWR are candidates to supplement radiosonde and satellite observations to feed modern numerical weather prediction (NWP) models through assimilation of their data. This has been recently investigated in a few sporadic cases, assimilating retrieved temperature and humidity profiles into NWP models (Cimini et al., 2012, 2014; Caumont et al., 2016). Martinet et al. (2015) illustrate the attempt to assimilating the primary observable, i.e. brightness temperature (TB) instead of retrieved profiles, within a simplified 1-D framework, showing positive impact on the NWP forecasts in the PBL. The development of the ground-based version of the fast radiative transfer model Radiative Transfer for TOVS (RTTOV), i.e. RTTOV-gb (De Angelis et al., 2016), allows the fast simulation of ground-based MWR TB, paving the way towards the operational assimilation of MWR TB into NWP models.

The quality of the analyses produced by data assimilation (DA) systems primarily relies on the accuracy of all used information such as the observations, the model forecast (i.e. the background), and the observation operator (the latter for modern DA systems such as variational systems and ensemble Kalman filters). Hence, the best estimate of the atmospheric state is obtained only if background and observation errors are correctly described and follow Gaussian distributions with zero mean. The representation of background and observation errors is thus essential in the assimilation system (Waller et al., 2016).

For modern DA techniques, the observation error can be attributed to the radiometric noise, observation operator, representativeness errors, and calibration uncertainties. The radiometric noise of the MWR is often known $(\sim 0.1-0.2 \mathrm{~K})$, well understood, and approximately uncorrelated between frequency channels (Hewison, 2006a). The occurring small correlations can be easily taken into account by observing the ambient black-body load included in the MWR hardware. Errors arising from the observation operator uncertainty in the context of radiative transfer modelling have been considered by De Angelis et al. (2016) for RTTOV-gb. These errors include uncertainty due to the spectroscopy parameters (dominant and most difficult to estimate accurately) and fast model parameterizations. The representativeness error corresponds to MWR fluctuations on smaller scales that cannot be represented by the NWP model. In general, the contributing error terms have similar magnitudes (Hewison, 2006a). However, it is also noticeable that channels near the water vapour line at $22 \mathrm{GHz}$ are dominated by spectroscopic uncertainties, while channels most sensitive to cloud liquid water $(31,51$, and $52 \mathrm{GHz})$ are dominated by their representativeness errors. Moreover, channels at 31,51 , and $52 \mathrm{GHz}$ are also sensitive to the water vapour continuum as well and to the spectroscopy of the $50-60 \mathrm{GHz}$ line complex. Finally, the highest-frequency channels $(>55 \mathrm{GHz})$, which are only sensitive to the temperature in the lowest few hundred metres, are dominated by radiometric noise (Hewison, 2006a).

Concerning calibration errors, Maschwitz et al. (2013) quantify the uncertainty for the tipping curve calibration in \pm 0.1 to $\pm 0.2 \mathrm{~K}(22-31 \mathrm{GHz})$ and \pm 0.6 to $\pm 0.7 \mathrm{~K}(51-$ $52 \mathrm{GHz}$, only to be applied at high-altitude sites with extremely low water vapour content), while they show an uncertainty of \pm 0.9 to $\pm 1.6 \mathrm{~K}(22-31 \mathrm{GHz}), \pm 0.5$ to $\pm 1.0 \mathrm{~K}$ (51-53 GHz), and \pm 0.2 to $\pm 0.3 \mathrm{~K}(54-58 \mathrm{GHz})$ for the liquid nitrogen calibration. To our knowledge, Maschwitz et al. (2013) presented the most complete uncertainty analysis of LN2 calibration available in the literature. However, there may be additional error sources (such as condensate on the radome, spurious reflections, and receiver sensitivity drifts) that could increase the total uncertainty in field conditions.

The background error covariance matrix plays an important role in data assimilation and analysis systems by spread- 
ing the information contained in the observation both in space and between variables through cross correlations. A good specification of background errors is thus an essential part of any state-of-the-art data assimilation system (Ingleby, 2001), since it affects the impact of the observations on the analysis.

The accuracy of NWP analysis systems is thus strongly dependent on appropriate statistics for both observation and background errors. Unfortunately, those statistics are not exactly known and their determination remains a major challenge in assimilation systems. Background errors are often determined using ensemble assimilation systems to compute the forecast differences between each member (Brousseau et al., 2011). Differences between observations and their background counterparts $(\mathrm{O}-\mathrm{B})$ are often used to determine observation error statistics (Desroziers et al., 2005). The O$\mathrm{B}$ monitoring in radiance space can reveal systematic errors coming from the measurements, the radiative transfer model, or the NWP forecast model (Hollingsworth et al., 1986; Stajner et al., 2004). This approach is widely used by the satellite data assimilation community, although it may not be always straightforward to differentiate the source of the systematic errors (Waller et al., 2016).

The bias arising from the $\mathrm{O}-\mathrm{B}$ monitoring can be removed to guarantee the assumption of unbiased observations, which is inherent to optimal estimation retrieval, such as the variational DA and ensemble Kalman filter schemes.

In this context, an accurate characterization of the MWR O-B departures represents an important step towards the operational exploitation of the so far under-exploited MWR instruments.

This paper illustrates the analysis of MWR O-B TB differences in clear-sky conditions during 1 year over a network of six instrumental sites in central Europe. Section 2 describes the dataset and the methodology used for this long-term OB monitoring. Section 3 discusses the results of this study, while Sect. 4 summarizes the findings and draws the final conclusions.

\section{Dataset and methodology}

\subsection{Ground-based microwave radiometer observations}

The microwave radiometer observations considered in this analysis consist of downwelling TB measured by six commercial ground-based MWR. The MWR is a passive remote sensing instrument that measures the radiance naturally emitted by the atmosphere at selected frequency channels in the 20-60 GHz range (Westwater et al., 2004). MWR represent a mature technique for the retrieval of atmospheric temperature and humidity profiles as well as integrated water vapour and liquid water path. MWRs provide retrievals in both clearand cloudy-sky conditions, with high temporal resolution, low-to-moderate vertical resolution, and most of the infor- mation content residing in the PBL. MWR channels near the $60 \mathrm{GHz}$ oxygen complex are used to retrieve temperature profiles, while channels near the $22.235 \mathrm{GHz}$ water vapour line provide humidity and integrated water vapour information and are also sensitive to the column integrated liquid water content. A first attempt of MWR networking in Europe was reported by Güldner et al. (2009) for a temporary network, while Cadeddu et al. (2013) describe the details of the MWR network belonging to the US Atmospheric Radiation Measurement program. In this study we consider the MWR units deployed permanently at six observing sites in central Europe (JOYCE, CESAR, LACROS, SIRTA, Payerne, and RAO - see details on Table 1). These instruments belong to different European institutions and were chosen to be representative of the MWR technology currently deployed in Europe. In addition, these six sites fall within the domain of the convective-scale model AROME-France (Seity et al., 2011), as shown in Fig. 1. These MWR are all multichannel temperature and humidity profilers; five are manufactured by RPG (HATPRO, Rose et al., 2005), while the remaining one (at RAO) is manufactured by Radiometrics (MP3000A; Ware et al., 2003). HATPRO detects radiances at 14 frequency channels $(22.24,23.04,23.84,25.44,26.24$, 27.84, 31.40, 51.26, 52.28, 53.86, 54.94, 56.66, 57.30, and $58.00 \mathrm{GHz})$. The first seven frequency channels are in the Kband $(22-31 \mathrm{GHz})$, while the last seven are in the $\mathrm{V}$-band (51-60 GHz). MP3000A detects radiances at 12 channels (5 in the K-band and 7 in V-band). Both MWR types have elevation scanning capabilities for improved temperature profiling in the boundary layer. The observations presented here are taken at six elevation angles $(90.0,42.0,30.0,19.2,10.2$, and $5.4^{\circ}$ ) for the HATPRO units and at two elevation angles (90.0 and $15.7^{\circ}$ ) for the MP3000A. The period considered in this study extends from 1 January to 31 December 2014. During this period, the MWR units undergo regular maintenance, including antenna radome cleaning, sanity checks, and absolute calibrations. The maintenance strategy is currently not harmonized across the network. Absolute calibration is commonly obtained via the cryogenic liquid nitrogen (LN2) calibration method. LN2 calibrations are typically performed once or twice a year to correct for instrument drifts. Note that faulty calibration may happen, manifesting as discontinuities in the time series of $\mathrm{O}-\mathrm{B}$ statistics (Löhnert and Maier, 2012). Temporal matching of MWR observations and NWP model forecasts has been obtained by selecting MWR TB records closest in time to the model forecast time (only one observation without any average over several). The following O-B analysis is performed on the sample of temporal match-up observation-model couples.

\subsection{NWP model}

The NWP model used in this study is AROME (Seity et al., 2010). AROME has a nonhydrostatic dynamical core inherited from the ALADIN-NH model (Bubnová et al., 1995) and 
Table 1. Sample size at all the instrumental sites before and after the quality control screening. Position, height, and reference of each instrument are reported. For HATPRO only, the generation family is also reported (G5 is currently commercialized).

\begin{tabular}{lrrrlrrl}
\hline Location & Lat & Long & $\begin{array}{r}\text { Height } \\
(\mathrm{m})\end{array}$ & MWR & $\begin{array}{r}\text { Pre- } \\
\text { screening }\end{array}$ & $\begin{array}{r}\text { Post- } \\
\text { screening }\end{array}$ & Reference \\
\hline JOYCE & 50.91 & 6.41 & 111 & HATPRO G2 & 602 & 557 & Löhnert et al. (2015) \\
LACROS & 51.35 & 12.43 & 125 & HATPRO G2 & 542 & 502 & Bühl et al. (2013) \\
Payerne & 46.82 & 6.95 & 491 & HATPRO G1 & 1087 & 955 & Collaud Coen et al. (2014) \\
SIRTA & 48.80 & 2.36 & 156 & HATPRO G2 & 1022 & 923 & Haeffelin et al. (2005) \\
CESAR & 51.97 & 4.93 & -0.7 & HATPRO G1 & 988 & 664 & CESAR (2017) \\
RAO & 52.21 & 14.12 & 125 & MP3000A & 709 & 680 & Neisser et al. (2002) \\
& & & & & & & RAO (2017) \\
\hline
\end{tabular}

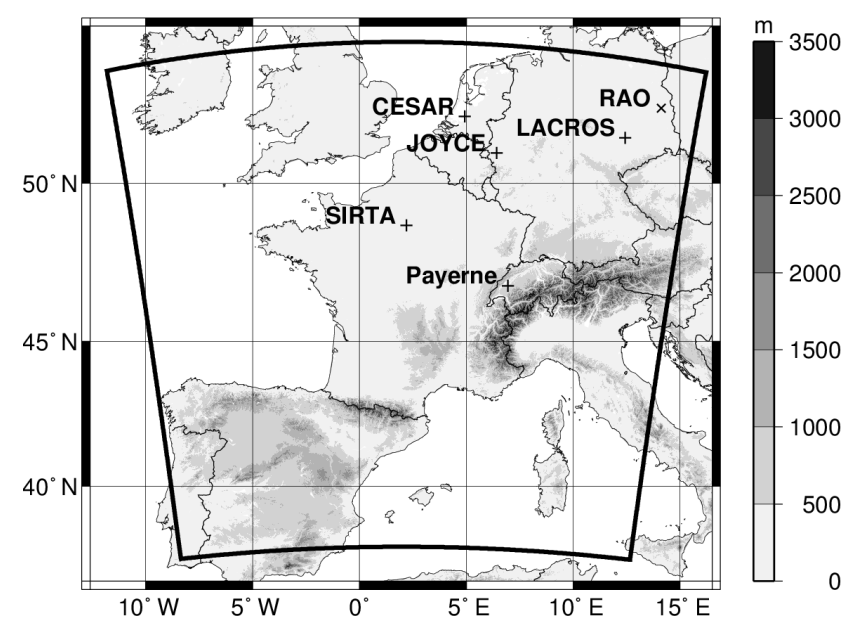

Figure 1. Topography $(\mathrm{m})$ and domain of AROME-France (large area delineated by solid black line). Locations of MWR sites are also shown $(+$ and $\times$ indicate, respectively, HATPRO and MP3000A).

physical parameterizations taken from the research model Meso-NH (Lafore et al., 1998). In 2014, the operational configuration AROME-France covered the domain shown in Fig. 1. The model had an horizontal resolution of $2.5 \mathrm{~km}$ and used 60 vertical levels, following the terrain in the lowest layers and the isobars in the upper atmosphere. The lateral boundary conditions were provided by the global ARPEGE NWP system (Courtier et al., 1991). AROME-France used a three-dimensional variational (3D-VAR) data assimilation system run in a rapid forward intermittent assimilation cycle; i.e. analyses were performed every $3 \mathrm{~h}$ starting from 00:00 UTC by assimilating all the observations available at Météo-France in order to provide new initial states for subsequent forecasts. The background error covariance matrices were specified through the use of an ensemble method (Brousseau et al., 2011). Data assimilated by the AROMEFrance DA system included observations from radiosondes, wind profilers, aircrafts, ships, buoys, automatic weather stations, satellites, GPS stations, and both Doppler radar wind velocity and radar reflectivity (Brousseau et al., 2014).
Temperature, humidity, and pressure profiles are extracted from the AROME-France $3 \mathrm{~h}$ forecasts and analyses. AROME-France cloud liquid water profiles are not available in the dataset used for this study. The profile extracted from the central point of the $3 \times 3$ model grid centred on each MWR site (i.e. closest in space to the MWR location) has been used as background.

\subsection{Radiative transfer model}

MWR TB are simulated at the specific frequency channel and elevation angle from the AROME-France thermodynamic profiles using the fast radiative transfer model RTTOVgb (De Angelis et al., 2016). RTTOV-gb has been developed modifying the RTTOV code (version 11.2) to simulate ground-based MWR observations, as the original RTTOV (Saunders et al., 1999) was meant to simulate downwardviewing satellite observations only.

Fast radiative transfer models perform simplified calculations of the atmospheric radiances by parameterizing the atmospheric transmittances. Accurate transmittances, computed with a slower line-by-line (LBL) model for a set of climatological atmospheric profiles, are used to calculate channel-specific regression coefficients in the training phase. Given these regression coefficients, the fast radiative transfer model can compute transmittances for any other input profile. The parameterization of the transmittances makes the radiative model computationally much more efficient and in principle should not add significantly to the errors generated by uncertainties in the spectroscopic data used by the LBL model on which the fast model is based (Matricardi et al., 2001). The additional uncertainty due to the use of RTTOV$\mathrm{gb}$ instead of a LBL model has been quantified in De Angelis et al. (2016).

The LBL model by Rosenkranz (1998) has been used for the water vapour and oxygen absorption to calculate the clear-sky transmittances needed in the RTTOV-gb regression coefficients computation (De Angelis et al., 2016). For the RTTOV-gb training we used 83 profiles, interpolated on 101 pressure levels and carefully chosen from a NWPSAF (Numerical Weather Prediction Satellite Application 
Facility) profile dataset to represent a wide range of physically realistic atmospheric states (Matricardi, 2008). These 101 pressure levels (ranging from 0.005 to $1050 \mathrm{hPa}$ ) have been specifically selected for ground-based perspective to be denser close to ground ( 34 levels below $2 \mathrm{~km}$; De Angelis et al., 2016).

In this work, the RTTOV-gb simulations consider the MWR channel bandwidth through the training performed by using LBL double sideband opacities. MWR detects radiance through narrow bandpass filters for each frequency channel. The nominal MWR channels are characterized by the midfrequency, which is a weighted average over the bandpass filter. In the RTTOV-gb training we consider a rectangular filter shape characterized by two frequencies equally weighted at the edges of the full width at half maximum (FWHM). For the RPG-HATPRO, the filter's FWHM is $0.23 \mathrm{GHz}$, except for the opaque V-band channels $(0.6-2.0 \mathrm{GHz}$; Rose et al., 2005). The FWHM is $0.30 \mathrm{GHz}$ at all the channels for the Radiometrics MP3000A (Solheim et al., 1998). RTTOVgb simulations take also into account atmospheric propagation effects due to Earth curvature and atmospheric refraction (Saunders et al., 2010). In this work, RTTOV-gb does not consider the finite antenna beamwidth as this feature is not available in the original RTTOV code. Thus, the antenna pattern, defining the region from where radiometer antennas receive their signal, is assumed as an ideal single pencil beam. This assumption becomes important only at low elevation angles, e.g. up to $1-1.5 \mathrm{~K}$ in $\mathrm{K}$-band at $5^{\circ}$ elevation angle (Meunier et al., 2013; Navas-Guzmán et al., 2016).

\subsection{Quality control (QC)}

Routine QC is applied by MWR instrument operators at the individual sites, resulting in a quality flag encoded within the data files. The complete datasets collected by each MWR in Table 1 have been transferred to a common centralized server. Then, MWR observations have been quality controlled before entering the O-B dataset. First of all, data flagged by the sanity/rain checks provided within the instrument data stream were discarded. In addition, we applied a cloud screening, as we intend to monitor O-B TB differences in clear-sky only to avoid the uncertainty stemming from the forecast and absorption of cloud liquid water. Clear-sky conditions have been selected using a two-stage screening: (i) $1 \mathrm{~h}$ standard deviation of the MWR TB at $30-31 \mathrm{GHz}\left(\sigma_{C}\right)$ and (ii) sky infrared temperature from the $10.5 \mu \mathrm{m}$ infrared radiometer mounted within the MWR housing $\left(T_{\mathrm{IR}}\right)$. Channels at $30-31 \mathrm{GHz}$ are the most sensitive to clouds as they are in a gas absorption window, where the signal is relatively insensitive to changes in atmospheric temperature and humidity. Thus, the TB standard deviation at $30-31 \mathrm{GHz}$ over a defined time period (e.g. $1 \mathrm{~h}$ ) can be used to indicate the presence of liquid clouds within the MWR field of view. In addition, the infrared radiometer (not available in Payerne, SIRTA, and CESAR) is sensitive to cloud base temperature and indicates the presence of thick clouds when the infrared temperature is high (meaning no contribution from the cold background above the cloud; Martinet et al., 2015). Thresholds for this screening procedure were determined in order to have a good compromise between a sufficient data sample and a high confidence of cloudy-sky rejections (Martinet et al., 2015). Periods with $\sigma_{C}>0.5 \mathrm{~K}$ (Turner at al., 2007) or $T_{\mathrm{IR}}>-30{ }^{\circ} \mathrm{C}$ (Martinet et al., 2015) were rejected. In addition, O-B TB differences larger than 3 standard deviations with respect to the mean difference were rejected to remove outliers (e.g. possible obstructions or undetected cloud contamination). Table 1 reports the sample size from each instrumental site before and after the QC screening.

\section{Results}

An example of $\mathrm{O}-\mathrm{B}$ monitoring is reported in Fig. 2, showing 1-year time series of the O-B TB differences at JOYCE for channels 22.24, 31.40, 52.28, and 58.00 GHz. Here, observations are TB measured by the HATPRO at zenith, while background are TB simulated with RTTOV-gb from the $3 \mathrm{~h}$ forecast profiles at the model grid column closest to JOYCE. It is evident that $\mathrm{O}-\mathrm{B}$ TB differences show different variance depending on the frequency, being largest at $22.24 \mathrm{GHz}$ and smallest at $58.0 \mathrm{GHz}$. O-B TB differences show to be quite steady, with the exception of channel $31.40 \mathrm{GHz}$; here a large difference (up to $10 \mathrm{~K}$ ) is evident until 3 June 2014 (Julian day 154). This misbehaviour was later confirmed by the instrument operator and it was attributed to a faulty calibration. In fact, 3 June 2014 corresponds to the date of the new LN2 absolute calibration at JOYCE, after which the observation comes closer to background again. This demonstrates that the O-B monitoring is able to detect instrument malfunctions, and it should be implemented and performed at each MWR site as part of its QC procedure. Similar misbehaviours were detected and later confirmed by instrument operators at other sites: specifically, (i) at CESAR at all the channels below $54 \mathrm{GHz}$ between 15 June and 18 September 2014 , corresponding again to a period after a faulty calibration; (ii) at CESAR at channel $22.24 \mathrm{GHz}$ and elevation angles below 42 degrees due to radio frequency interference leaking into the channel bandpass filter; (iii) at Payerne at $26.24 \mathrm{GHz}$ for the whole period due to an unknown malfunction possibly related to hardware components causing large observed TB variations.

Figure 3 shows the O-B TB statistics for the six instrumental sites at zenith (i.e. $90^{\circ}$ elevation angle). The reported bias, standard deviation (SD), and root mean square (RMS) are computed from the QC dataset. Note that periods of instrument malfunctions have been removed in JOYCE (before Julian day 154) and CESAR (Julian days between 165 and 261) by discarding the data before computing the statistics. The $26.24 \mathrm{GHz}$ channel misbehaviour in Payerne has not been removed because the source is still unidenti- 

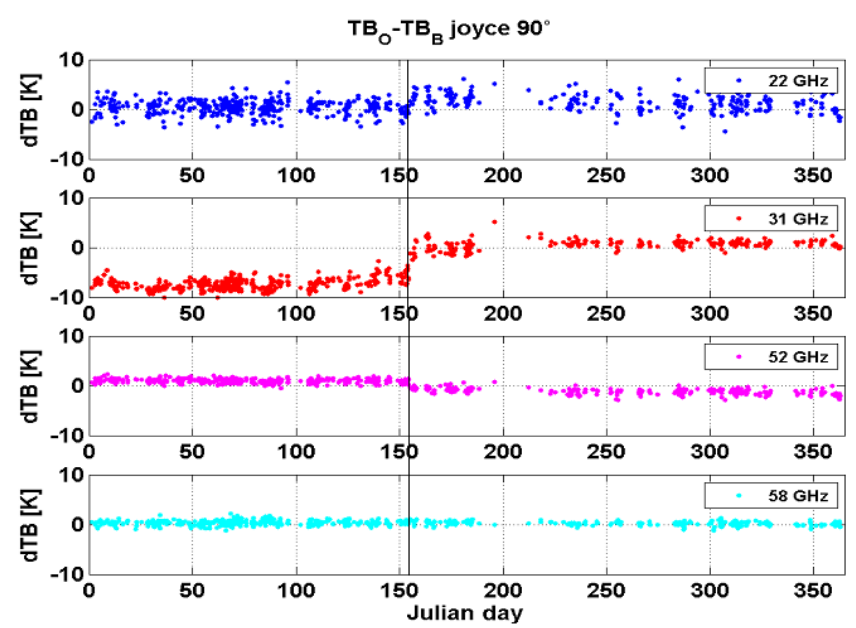

Figure 2. Time series of the O-B TB differences at JOYCE; from top to bottom: channels 22.24 (blue dots), 31.40 (red dots), 52.28 (magenta dots), and $58.00 \mathrm{GHz}$ (cyan dots). The black solid line represents the date of the new calibration (3 June 2014).

fied and it also affects the whole dataset. Accordingly, bias, $\mathrm{SD}$, and RMS for this channel show a peak, reaching -3 , 2 , and $4 \mathrm{~K}$, respectively. SD statistics for the K-band channels show very similar behaviour from site to site, decreasing from the line centre towards the high-frequency wing. This may suggest that the $\mathrm{O}-\mathrm{B}$ difference is mostly due to an uncertainty in the humidity profile forecast. For example, at JOYCE the SD ranges from $1.6 \mathrm{~K}$ at $22.24 \mathrm{GHz}$ to $0.7-0.8 \mathrm{~K}$ at $27.84 / 31.40 \mathrm{GHz}$. Note that channels close to the $22.24 \mathrm{GHz}$ line centre show the highest values of TB and the highest dynamic range in clear-sky conditions. Thus, the large absolute uncertainty at these channels may correspond to similar relative accuracy when compared to the other Kband channels.

The maximum RMS and biases are located at $22.24 \mathrm{GHz}$ at all the sites except RAO, where they are at $23.04 \mathrm{GHz}$ (around 2.5 and $2.0 \mathrm{~K}$, respectively). At JOYCE the bias and RMS range, respectively, from 0.9 and $1.8 \mathrm{~K}$ at $22.24 \mathrm{GHz}$ to 0.1 and $0.7 \mathrm{~K}$ at $27.84 \mathrm{GHz}$. Albeit one may not expect the variability to increase in the window channel, we see slightly larger differences at $31.40 \mathrm{GHz}$ with respect to $27.84 \mathrm{GHz}$ (bias and RMS equal to 0.8 and $1.3 \mathrm{~K}$, respectively), which may be attributed to few undetected cases of cloud contamination. Similar statistics are reported at all sites except LACROS. At LACROS we see similar standard deviations but larger bias and, consequently, RMS (ranging from 1.7 to $3.6 \mathrm{~K}$ in K-band, with maximum value at $22.24 \mathrm{GHz}$ ). The reason for these larger biases is still under investigation.

$\mathrm{O}-\mathrm{B}$ statistics at V-band show different behaviour at lower-frequency (i.e. transparent) and higher-frequency (i.e. opaque) channels. Opaque channels $(54-58 \mathrm{GHz})$ show low bias, SD, and RMS (all within $0.9 \mathrm{~K}$ ) as the atmosphere is opaque due to oxygen and therefore water vapour and the effect of clouds on observed TB is negligible at these channels. Transparent channels (51-53 GHz) show rather large biases (2-3 K and up to $5 \mathrm{~K}$ in Payerne) with relatively low SD $(1.0-1.5 \mathrm{~K})$. Bias values of the same order of magnitude for the $51-53 \mathrm{GHz}$ range were previously reported (Hewison et al., 2006b; Löhnert and Maier, 2012; Martinet et al., 2015; Blumberg et al., 2015; Navas-Guzmán et al., 2016), employing MWR of different types and manufacturers. Large biases at lower V-band channels $(50-54 \mathrm{GHz})$ are likely due to a combination of systematic uncertainties stemming from inaccurate instrument bandpass characterization, calibration and absorption model. In fact, these channels are located on a steep shoulder of the $\mathrm{O}_{2}$ absorption complex and thus are sensitive to uncertainty in bandpass modelling. In addition, they suffer from larger calibration uncertainty due to the relative low opacity as well as larger radiative transfer model errors due to the lack of well-calibrated data usable for tuning spectroscopic parameters. However, it is important to note that the standard deviation remains below $1 \mathrm{~K}$, allowing for an easy bias correction. In this study, a bias correction based on simulated TB computed from clear-sky NWP model profiles can thus be applied on the measurements.

Figure 4 shows O-B statistics for zenith MWR observations in JOYCE, before and after such a bias correction. Ideally, the bias correction should be computed using the same NWP and radiative transfer models used for the O-B, as done in operational systems. However, applying such a bias correction on this same dataset, the resulting bias would of course be zero. Thus, aiming to a qualitative demonstration of the bias correction, we use here independent bias correction values computed for JOYCE with respect to another NWP model. The correction values were computed by a previous work considering the DWD COSMO-DE model (Baldauf et al., 2011), using forecasts not older than $3 \mathrm{~h}$ at the closest vertical column to JOYCE. The radiative transfer models are also different, though both adopt the atmospheric absorption model of Rosenkranz (1998). All clear-sky observations between two absolute calibrations have been used to compute the V-band biases by considering simultaneous observations and forward modelled TB. This approach assumes a constant bias between two adjacent calibrations, which has been justified for a HATPRO system by Löhnert and Maier (2012). In this way, the TB biases in the V-band are decreased from $1-1.5$ to $0.1-0.5 \mathrm{~K}$ between 51 and $53 \mathrm{GHz}$ (Fig. 4). Note that the bias correction is applied to the Vband channels only, since the humidity uncertainty affecting the model and the colocation is deemed too high to provide a reliable bias correction for the K-band channels. A different approach using NWP model output to adjust microwave observations for operational applications is discussed by Güldner (2013).

Although the caveats described above make the bias correction results only qualitative, we can see a significant improvement in the $\mathrm{O}-\mathrm{B}$ statistics, demonstrating that a bias correction would remove most of the systematic errors at 51- 

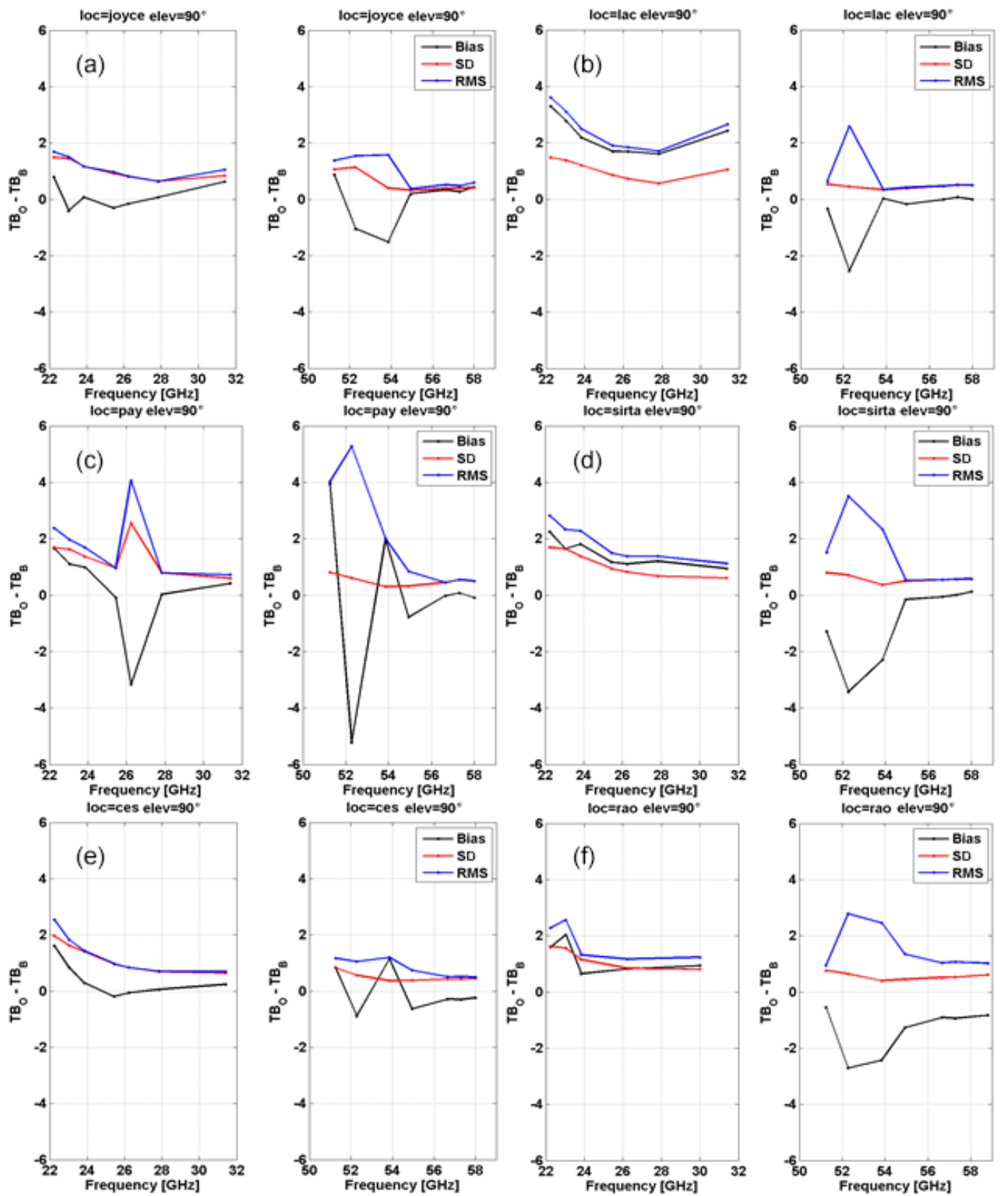

Figure 3. Statistics of the differences between observations and background TB. Observations are TB measured by ground-based MWR. Background counterparts are TB simulated with RTTOV-gb from AROME-France $3 \mathrm{~h}$ forecast profiles in clear-sky conditions at zenith. Panels (a), (b), (c), (d), (e), and (f) refer, respectively, to JOYCE, LACROS, Payerne, SIRTA, CESAR, and RAO. Biases are shown with black lines, standard deviations with red lines, and RMS with blue lines.

$53 \mathrm{GHz}$, on the assumption of consistent NWP and radiative transfer models. Apart from this qualitative demonstration, a consistent bias correction, computed using the same NWP and radiative transfer models used for the $\mathrm{O}-\mathrm{B}$, is highly recommended for any further use of this dataset.

Table 2 reports the O-B TB mean differences (i.e. biases) and their $95 \%$ confidence intervals, for each instrumental site at zenith.
Observations at different elevation angles allow to check the robustness of the previous results. Figure 5 shows the statistics at JOYCE at elevation angles 90.0, 42.0, 30.0, 19.2, 10.2 , and $5.4^{\circ}$. Results at K-band show similar tendencies at lower elevation angles (panels B to F). However, the variability increases with decreasing elevation angle because uncertainty in the AROME-France humidity profile gets amplified with increasing air mass. This happens also due to a 
Table 2. Biases of O-B TB differences and their $95 \%$ confidence intervals for all the instrumental sites at zenith. Values at RAO (MP3000A) are reported on the column of the closest HATPRO frequency channel.

\begin{tabular}{|c|c|c|c|c|c|c|c|}
\hline $\begin{array}{l}\text { Chan } \\
\text { (GHz) }\end{array}$ & 22.24 & 23.04 & 23.84 & 25.44 & 26.24 & 27.84 & 31.40 \\
\hline JOYCE & $0.791 \pm 0.124$ & $-0.411 \pm 0.121$ & $0.075 \pm 0.098$ & $-0.303 \pm 0.077$ & $-0.148 \pm 0.067$ & $0.068 \pm 0.053$ & $0.630 \pm 0.114$ \\
\hline LACROS & $3.288 \pm 0.130$ & $2.776 \pm 0.121$ & $2.179 \pm 0.105$ & $1.698 \pm 0.075$ & $1.688 \pm 0.063$ & $1.605 \pm 0.049$ & $2.425 \pm 0.093$ \\
\hline Payerne & $1.666 \pm 0.107$ & $1.105 \pm 0.103$ & $0.995 \pm 0.087$ & $-0.085 \pm 0.061$ & $-3.156 \pm 0.162$ & $0.029 \pm 0.050$ & $0.409 \pm 0.038$ \\
\hline SIRTA & $2.243 \pm 0.110$ & $1.645 \pm 0.106$ & $1.810 \pm 0.089$ & $1.161 \pm 0.061$ & $1.105 \pm 0.053$ & $1.203 \pm 0.043$ & $0.943 \pm 0.039$ \\
\hline CESAR & $1.615 \pm 0.150$ & $0.840 \pm 0.124$ & $0.293 \pm 0.117$ & $-0.190 \pm 0.073$ & $-0.061 \pm 0.064$ & $0.065 \pm 0.053$ & $0.243 \pm 0.050$ \\
\hline RAO & $1.588 \pm 0.122$ & $2.032 \pm 0.117$ & $0.647 \pm 0.086$ & & $0.821 \pm 0.063$ & & $0.940 \pm 0.060$ \\
\hline $\begin{array}{l}\text { Chan } \\
(\mathrm{GHz})\end{array}$ & 51.26 & 52.28 & 53.86 & 54.94 & 56.66 & 57.30 & 58.00 \\
\hline JOYCE & $0.874 \pm 0.089$ & $-1.052 \pm 0.095$ & $-1.519 \pm 0.034$ & $0.196 \pm 0.027$ & $0.337 \pm 0.033$ & $0.275 \pm 0.033$ & $0.428 \pm 0.035$ \\
\hline LACROS & $-0.341 \pm 0.047$ & $-2.536 \pm 0.039$ & $0.026 \pm 0.030$ & $-0.179 \pm 0.034$ & $-0.009 \pm 0.042$ & $0.066 \pm 0.044$ & $-0.004 \pm 0.044$ \\
\hline Payerne & $3.941 \pm 0.051$ & $-5.230 \pm 0.039$ & $1.978 \pm 0.019$ & $-0.781 \pm 0.020$ & $-0.017 \pm 0.029$ & $0.082 \pm 0.035$ & $-0.090 \pm 0.031$ \\
\hline SIRTA & $-1.284 \pm 0.051$ & $-3.425 \pm 0.046$ & $-2.301 \pm 0.023$ & $-0.153 \pm 0.033$ & $-0.064 \pm 0.035$ & $0.012 \pm 0.037$ & $0.121 \pm 0.037$ \\
\hline CESAR & $0.838 \pm 0.062$ & $-0.883 \pm 0.043$ & $1.139 \pm 0.029$ & $-0.632 \pm 0.029$ & $-0.279 \pm 0.033$ & $-0.300 \pm 0.032$ & $-0.233 \pm 0.034$ \\
\hline RAO & $-0.549 \pm 0.057$ & $-2.706 \pm 0.048$ & $-2.429 \pm 0.031$ & $-1.262 \pm 0.034$ & $-0.905 \pm 0.039$ & $-0.932 \pm 0.039$ & $-0.831 \pm 0.045$ \\
\hline
\end{tabular}
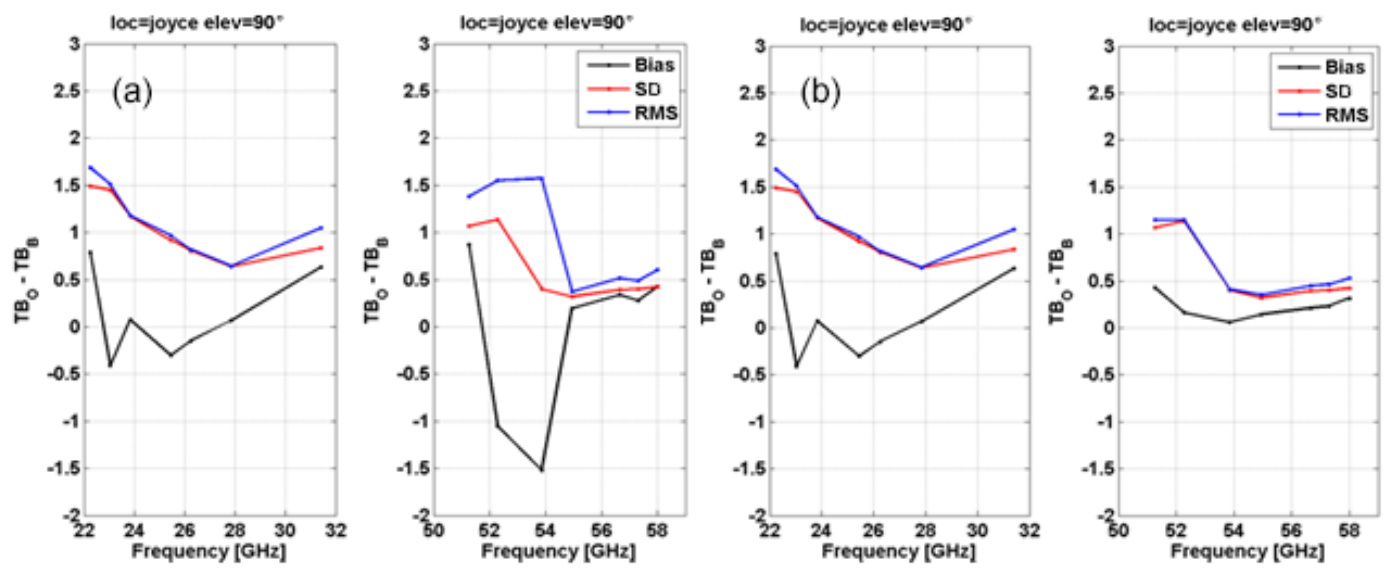

Figure 4. Statistics of the differences between observations and background TB, as in Fig. 3. Here, results from JOYCE at zenith are shown. Panels (a) and (b) refer, respectively, to before and after the bias correction with the COSMO-DE model. Biases are shown with black lines, standard deviations with red lines, and RMS with blue lines.

stronger TB signal, resulting in larger absolute noise. Statistics follow a similar trend up to $19.2^{\circ}$ elevation angle, where RMS reaches $6 \mathrm{~K}$. Larger differences are found at 10 and $5^{\circ}$ elevation angles in K-band (biases, SD, and RMS, respectively, up to 16,8 , and $18 \mathrm{~K}$ at $5^{\circ}$ ) probably due to (i) the current version of RTTOV-gb not being designed for elevation angles lower than $15^{\circ}$ (De Angelis et al., 2016), as simulations at low elevation angles were not necessary in the original satellite perspective; and (ii) the violation of the homogeneity assumption, which needs to be satisfied when using low elevation angles. This may also be due to the fact that 10 and $5^{\circ}$ are outside the elevation angle range used in the RTTOV-gb training configuration (elevation angle set between 90 and 16 $6^{\circ}$; De Angelis et al., 2016). Moreover, while RTTOV-gb considers Earth curvature, bandwidth, and atmospheric refraction (as explained in Sect. 2.3), it currently does not take into account the antenna beam width; this aspect can cause large biases between simulations and observations at very low elevation angles.

Statistics at V-band opaque channels show little variation with elevation angle. The zenith systematic O-B differences in the 52.28 and $53.86 \mathrm{GHz}$ channels decrease with decreasing elevation angle due to the fact that atmosphere becomes more and more opaque. However, the systematic difference at $51.26 \mathrm{GHz}$ stays between 1 and $2 \mathrm{~K}$, independent of elevation angle. Here, the systematic offset at zenith (possibly due to calibration uncertainty) is probably taken over by effects of not considering the antenna beam width at low elevation angles (see Meunier et al., 2013, Fig. 14). The statistics of random uncertainty (i.e. SD) follow a similar trend with elevation angle at all the instrumental sites (figures for all sites are reported in the Supplement). 

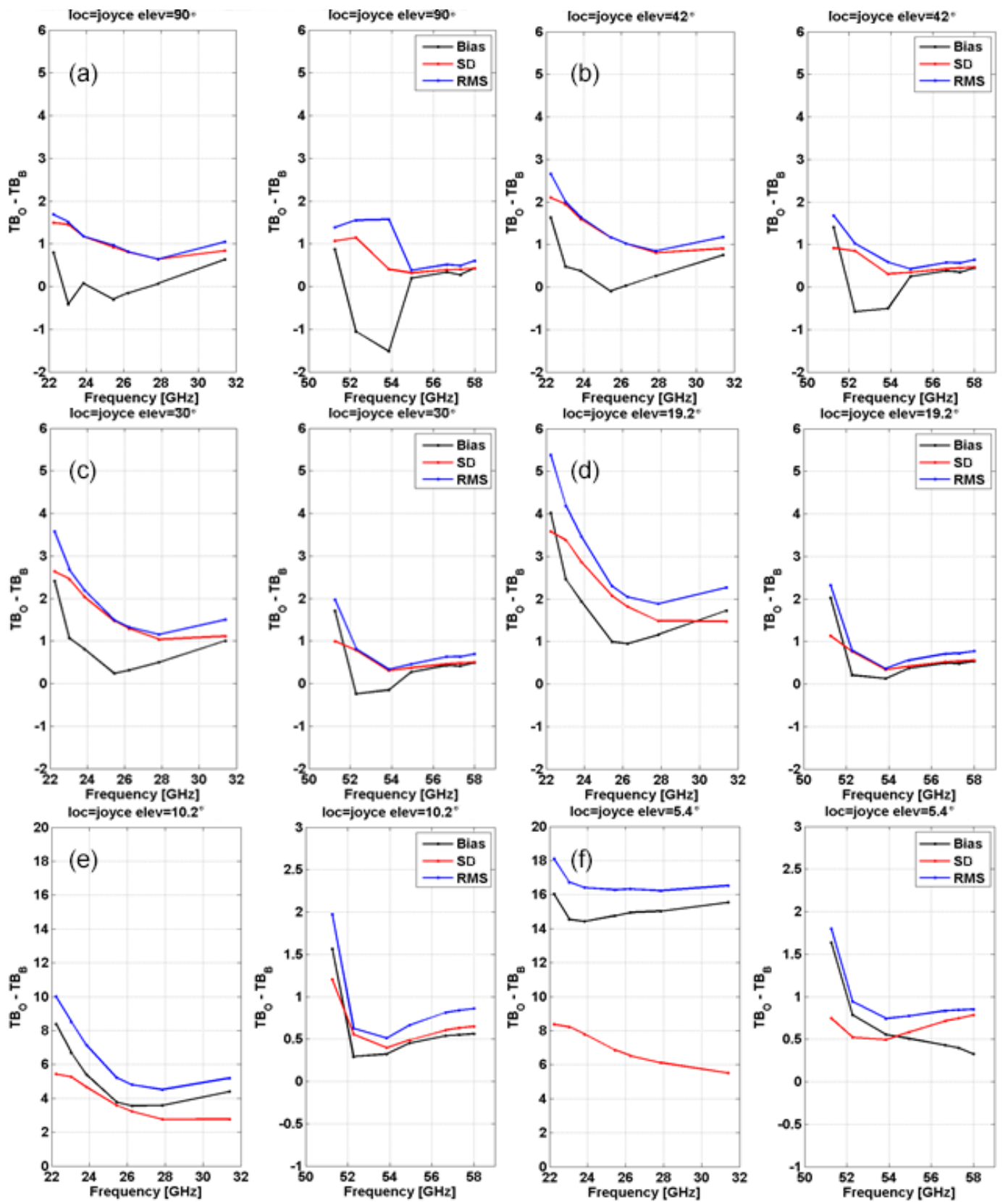

Figure 5. Statistics of the differences between observations and background TB, as in Fig. 3. Here, results from JOYCE at different observing angle are shown. Panels (a), (b), (c), (d), (e), and (f) refer, respectively, to 90, 42, 30, 19.2, 10.2, and 5.4 elevation angle. Biases are shown with black lines, standard deviations with red lines, and RMS with blue lines.

Note that both the clear-sky selections performed with the IR measurements and the $31 \mathrm{GHz}$ standard deviations only refer to zenith observations. This may not be fully representative of off-zenith measurements. Ancillary data providing cloud presence at other elevation angles (such as those provided by whole-sky imagers) are not available at the considered MWR sites. In addition, the aim of this study is to present a method that can be applied to any site where a MWR instrument is operated alone. The uncertainty due to residual off-zenith cloud contamination may contribute to enhanced O-B differences at lower elevation angles, possibly adding to both bias and standard deviation. However, cloud contamination does not significantly affect V-band opaque channels, which are those used at lower elevation for boundary layer temperature profile retrievals.

Moreover, O-B statistics are found to be consistent among the instrumental sites (in particular standard deviations) down to $10^{\circ}$ elevation angle; this seems to suggest that no 

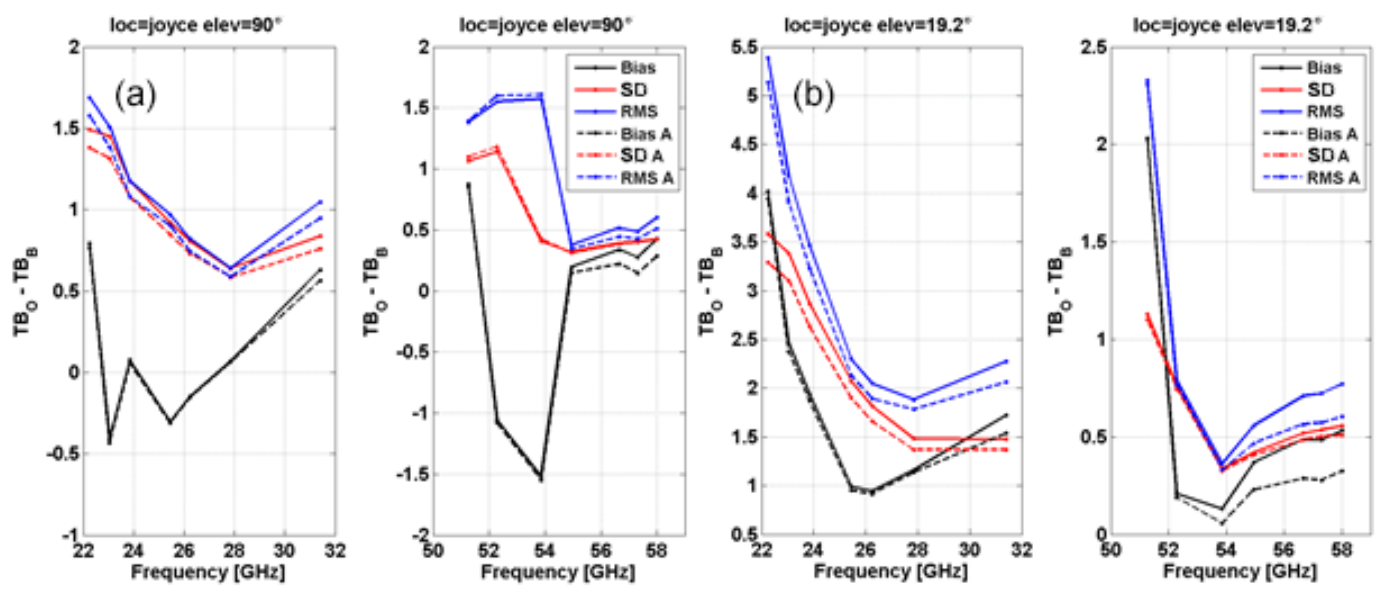

Figure 6. Statistics of the differences between TB observations and model background (solid lines) and between TB observations and model analysis (dashed lines). Simulated TB are computed with RTTOV-gb from AROME-France $3 \mathrm{~h}$ forecast (solid lines) and AROME-France analyses (dashed lines) profiles in clear-sky conditions for Joyce at zenith. Panels (a) and (b) refer, respectively, to 90 and $19.2^{\circ}$ elevation angle. Biases are shown with black lines, standard deviations with red lines, and RMS with blue lines.

significant site-specific contamination is affecting the comparison.

Figure 6 shows the statistics of $\mathrm{O}-\mathrm{B}$ differences as well as observation minus analysis $(\mathrm{O}-\mathrm{A})$, in which the AROME analysis is used instead of the $3 \mathrm{~h}$ forecast as background. The AROME analysis is the result of the blending of the AROME $3 \mathrm{~h}$ forecast with all the observations available at Météo-France (from satellites, radiosondes, surface networks, etc., but not from MWRs) at the same time. O-B and O-A statistics at JOYCE, elevation angles 90 and $19.2^{\circ}$, are shown. O-B and O-A biases are similar at both elevation angles in the K-band and in the V-band's more transparent channels. Thus, forecast and analysis compare almost equally to MWR observations; despite the large number of observations assimilated into the analyses (but not into the $3 \mathrm{~h}$ forecasts), O-B and O-A statistics are almost identical. This seems to indicate that the newly assimilated data did not bring significant information to the analysis with respect to forecast in terms of MWR observables. Assuming the observations as the reference, and considering that MWR uncertainty for transparent channels is typically smaller than the RMS in Fig. 6, this may suggest that the assimilated data perhaps provide little information where it would be useful (e.g. in the boundary layer). In this perspective, the assimilation of MWR brightness temperatures into NWP may provide useful information in the boundary layer. Considering V-band opaque channels, we note smaller biases for $\mathrm{O}-\mathrm{A}$ than $\mathrm{O}-$ B differences (up to $40 \%$ smaller at $19.2^{\circ}$ ). These channels are mostly sensitive to temperature profile in the PBL, and thus this result suggests that most of the $3 \mathrm{~h}$ forecast errors point toward the PBL. PBL is indeed the atmospheric layer where most of the information provided by MWRs is located, though this may be redundant with that of other assimilated observations (e.g. radiosondes). Quantification of the infor- mation brought by MWR into NWP data assimilation will be the subject of future research.

Note that O-A SDs are slightly lower than or equal to the corresponding O-B SDs at all the frequency channels; this is consistent with the assumptions that the analysis variance is lower than or equal to the background variance, and the observation errors and the model errors (either analysis or background) are independent. These assumptions are usually made in modern DA techniques.

In addition to unbiased observations, another hypothesis common to variational and ensemble Kalman filter-based DA systems is that the observations and background errors are Gaussian, which implies that the distribution of the O-B TB differences is Gaussian. This assumption has been verified by exploiting excess kurtosis and skewness scores. Kurtosis can be formally defined as the standardized fourth population moment about the mean of a specific distribution. The normal distribution has a kurtosis of 3 , and thus the "excess kurtosis" is usually used (i.e. kurtosis -3 ). A distribution with positive excess kurtosis has heavier tails and a higher peak than the normal distribution, whereas a distribution with negative excess kurtosis has lighter tails and is flatter. Skewness is formally the third central moment of the specific distribution, divided by the cube of its standard deviation, and it is a measure of symmetry, or more precisely, the lack thereof. A positive skewness value indicates positive (right) skew; a negative value indicates negative (left) skew. The higher the absolute value is, the greater the skew.

For both excess kurtosis and skewness, a normal distribution should return a score of 0 . In general, fair approximations to normal distribution should have skewness and excess kurtosis within -1 and +1 (Bulmer, 1979). Figure 7 shows two histograms of O-B TB differences at $90^{\circ}$ elevation angle, for JOYCE $(58.00 \mathrm{GHz})$ and Payerne $(52.28 \mathrm{GHz})$. The 

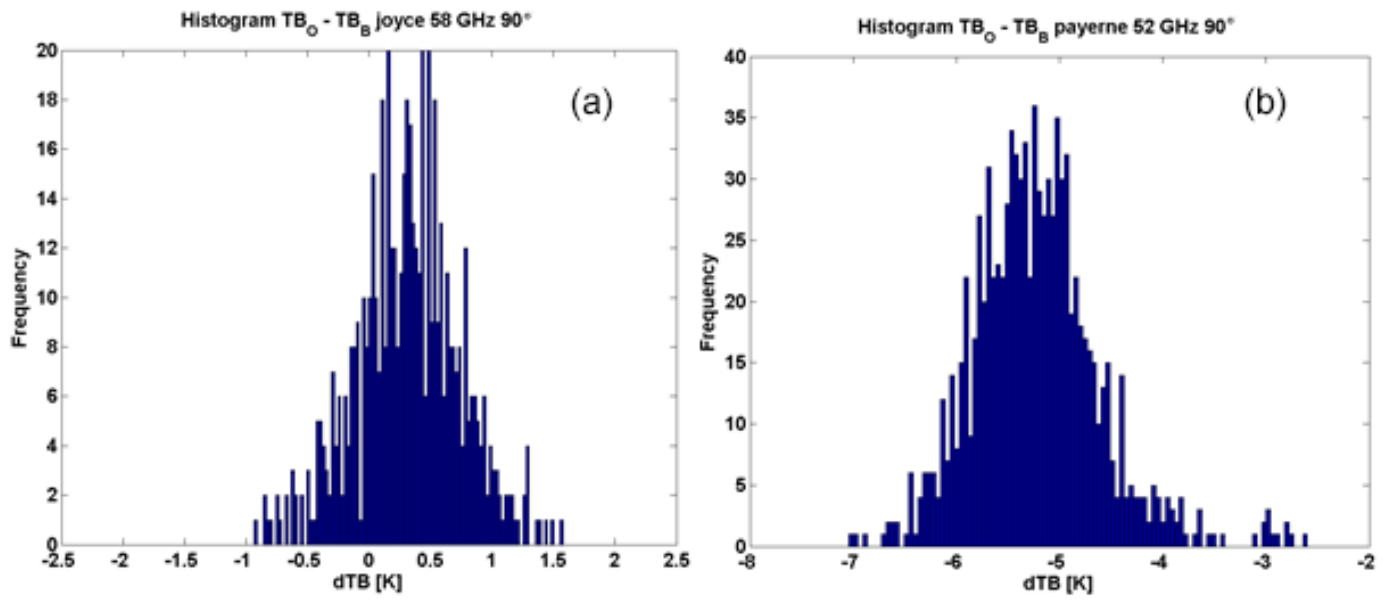

Figure 7. Histograms of the O-B TB differences. Panel (a) refers to JOYCE at $58.00 \mathrm{GHz}$ and $90^{\circ}$ elevation angle, while panel (b) refers to Payerne at $52.28 \mathrm{GHz}$ and $90^{\circ}$ elevation angle.

histogram at JOYCE shows a distribution approximately Gaussian, with excess kurtosis 0.15 and skewness -0.07 . Conversely, the distribution at Payerne has heavier tails (excess kurtosis 1.86) than Gaussian and moderate asymmetry (skewness 0.72). Figures 8 and 9 show, respectively, excess kurtosis and skewness as function of frequency, at each instrumental site and for elevation angles 90.0, 42.0, 19.2 (15.7 for RAO), and $10.2^{\circ}$. In general, excess kurtosis is within \pm 1 , demonstrating fair approximation to Gaussian error. Excess kurtosis above 2 is reported for Payerne at $51-53 \mathrm{GHz}$ and $90-42^{\circ}$ elevation and for CESAR at $22.24 \mathrm{GHz}$ and $42^{\circ}$ elevation. These same channels are also characterized by large O-B TB statistics, as shown in Fig. 3 and in the Supplement. Above $10^{\circ}$ elevation, absolute values of excess kurtosis slightly exceeding 1 are reported for RAO at $23.04 \mathrm{GHz}$ and $15.7^{\circ}$ and for LACROS at $51.26 \mathrm{GHz}$ and $19.2^{\circ}$. At $10^{\circ}$, kurtosis around 1.3-1.5 is reported for Payerne (31.40, 51.26, and $52.28 \mathrm{GHz})$ and for CESAR $(51.26 \mathrm{GHz})$. In general, the absolute value of the skewness is within 0.5 in K-band (22$28 \mathrm{GHz})$ and in the V-band opaque channels $(54-58 \mathrm{GHz})$ at each instrumental site, meaning approximately symmetric distributions. The only exception is CESAR at $22 \mathrm{GHz}$ and $42^{\circ}$, where skewness is 1.2. Larger skewness are reported for more transparent channels $(31,51$, and $52 \mathrm{GHz})$, in particular for Payerne $\left(52 \mathrm{GHz}\right.$, elevation angles 90 and $42^{\circ}$, up to $0.9)$ and for Joyce $\left(51 \mathrm{GHz}, 10^{\circ}\right.$ elevation angle, up to 1.1$)$, demonstrating moderate asymmetry. In summary, of the 328 channel and elevation angle combinations that were evaluated, only $4.2 \%(0.6 \%)$ showed an absolute value of excess kurtosis (skewness) larger than 1 . Among these are the channels that showed large O-B statistics and are thus suspect of instrumental misbehaviour.
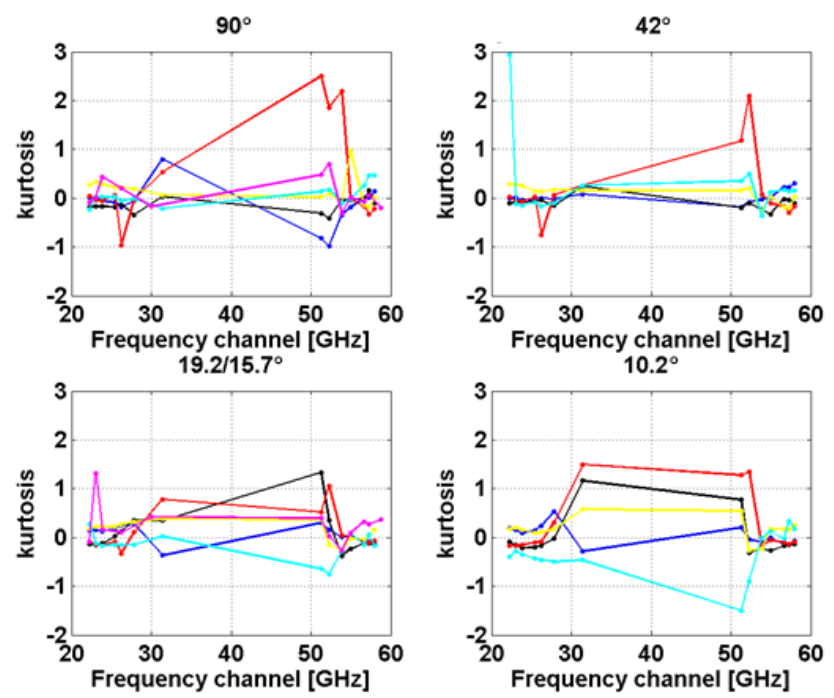

Figure 8. Excess kurtosis as function of frequency for elevation angles 90.0, 42.0, 19.2 (15.7 for RAO), and 10.2 . Scores for JOYCE, LACROS, Payerne, SIRTA, CESAR, and RAO are reported, respectively, in blue, black, red, yellow, cyan, and magenta.

\section{Summary and conclusions}

This work illustrates the first O-B analysis of ground-based TB observations from an European network of six MWRs over a 1-year period (2014). Statistics of the differences between MWR observations and their NWP model background counterparts can be used to shed light on observation and background errors. The knowledge of these errors is crucial for data assimilation because observations and short-term model forecasts are the primary sources of information used to produce analyses. Moreover, the $\mathrm{O}-\mathrm{B}$ monitoring is essential to detect and possibly remove any systematic errors 

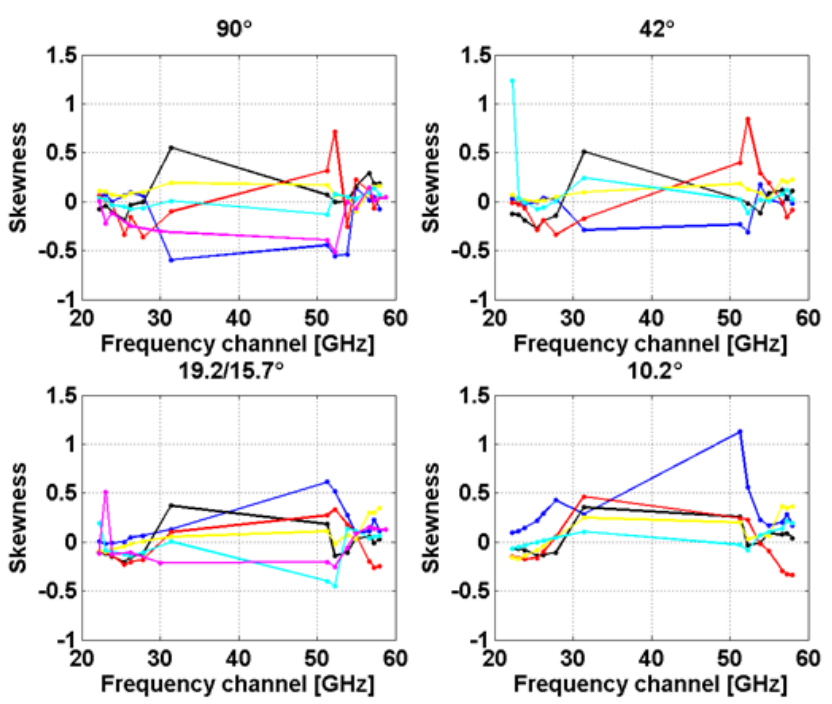

Figure 9. Skewness as function of frequency for elevation angles 90.0, 42.0, 19.2 (15.7 for RAO), and 10.2 ${ }^{\circ}$. Scores for JOYCE, LACROS, Payerne, SIRTA, CESAR, and RAO are reported, respectively, in blue, black, red, yellow, cyan, and magenta.

coming from the MWR measurements, the radiative transfer model, or the NWP model forecast.

In this analysis, observations are MWR TB measured by two types of commercial MWR (RPG-HATPRO and Radiometrics' MP3000A). Background counterparts are TB simulated with the fast radiative transfer model RTTOV-gb from the AROME-France $3 \mathrm{~h}$ forecasts and analyses. Quality control and clear-sky selection are performed with a three-stage screening based on the $1 \mathrm{~h}$ standard deviation of the MWR $\mathrm{TB}$ at $31 \mathrm{GHz}$, the infrared radiometer TB, and the quality/rain flag provided by the manufacturer.

It is shown how $\mathrm{O}-\mathrm{B}$ monitoring can be used to detect instrument malfunctions by exploiting the time series of the O-B TB differences. The results strongly suggest an operational implementation of this monitoring at all sites deploying a MWR as part of the QC procedure.

Observations minus background statistics are quite consistent between the instrumental sites. They decrease in Kband at zenith from the $22.24 \mathrm{GHz}$ line centre (SD $~ 1.5-$ $2.0 \mathrm{~K})$ towards the high-frequency wing ( $\mathrm{SD} \sim 0.5-1.0 \mathrm{~K}$ ). V-band opaque channels $(54-58 \mathrm{GHz})$ show low statistics (RMS within 0.8-0.9 K) due to the saturation and the dependence to only temperature. V-band more transparent channels (51-53 GHz) show large biases (up to $5 \mathrm{~K}$ in Payerne) with relatively low SD $(1.0-1.5 \mathrm{~K})$, demonstrating that these biases can be effectively removed by applying a bias correction based on TB simulated from a NWP model (if the forecast errors are within the expected accuracy).

Bias, standard deviation, and RMS at K-band increase with decreasing elevation angle, following a similar trend. Large differences are found at low $\left(5-10^{\circ}\right)$ elevation angles
(RMS up to $20 \mathrm{~K}$ ) due to atmospheric inhomogeneity and known RTTOV-gb limitations at elevation angles below $15^{\circ}$. Statistics at V-band opaque channels show only small variations with the elevation angle. The $\mathrm{O}-\mathrm{B}$ mean differences decrease at 52.28 and $53.86 \mathrm{GHz}$ and increase at $51.26 \mathrm{GHz}$ with decreasing elevation angles.

The observations minus analysis TB statistics are similar to the $\mathrm{O}-\mathrm{B}$, except for a bias deflection (up to $40 \%$ ) in the V-band opaque channels, especially at low elevation angles. This suggests the possible level of improvement that may be expected by assimilating MWR TB into NWP models, at least for boundary layer temperature profiling.

The Gaussian error assumption, typical of variational and ensemble Kalman filter-based DA systems, has been evaluated by computing excess kurtosis and skewness scores of the O-B TB distributions. Among the evaluated angle/channel combinations, excess kurtosis and skewness are typically within, respectively, $1(95.8 \%)$ and $0.5(99.4 \%)$. This demonstrates that $\mathrm{O}-\mathrm{B}$ TB distributions are typically Gaussian with good approximation. Larger scores (excess kurtosis and skewness above 2 and 1) are reported for Payerne at $51-53 \mathrm{GHz}$ and high elevation angles $\left(90-42^{\circ}\right)$ and for Cesar at $22.24 \mathrm{GHz}$ and $42^{\circ}$ elevation angle. These scores result in O-B TB distributions with moderate asymmetry and heavier tails than Gaussian, possibly due to instrument malfunction or radio frequency interference.

In conclusion, the presented $\mathrm{O}-\mathrm{B}$ analysis demonstrated the typical operational performances of a prototype network of six MWR in Europe, showing

1. robust and mature technology, suitable for operational use;

2. continuous TB observations, typically stable and reliable, whose quality can be monitored remotely;

3. consistent $\mathrm{O}-\mathrm{B}$ statistics throughout the network;

4. moderate O-B systematic differences that can be effectively addressed through bias correction;

\section{5. typically Gaussian O-B distributions.}

This work provides a comprehensive characterization of the MWR O-B statistics and distributions that may serve as a reference for the other MWR currently deployed in Europe and worldwide, including commercial (e.g. Attex MTP-5) and research types (e.g. TEMPERA; Navas-Guzman et al., 2016). It also represents a step towards the operational exploitation of ground-based MWRs, thus far under-exploited instruments which may play a crucial role in the accurate characterization of boundary layer thermodynamics into NWP models.

Data availability. The dataset used for this analysis is available from the authors upon request. 


\section{The Supplement related to this article is available online at https://doi.org/10.5194/amt-10-3947-2017-supplement.}

Competing interests. The authors declare that they have no conflict of interest.

Acknowledgements. This work has been stimulated through the COST Action ES1303 (TOPROF), supported by COST (European Cooperation in Science and Technology). Part of the work was supported by the EU H2020 project GAIA-CLIM (Ares(2014)3708963/project 640276). The JOYCE observations and data analysis have been supported through the German Science Foundation DFG under grant LO 901/7-1. RAO, LACROS, JOYCE, and CESAR observations have also been supported through the German BMBF research initiative $\mathrm{HD}(\mathrm{CP})^{2}$ under grants FKZ01LK1209A-E and FKZ01LK1502A. Thanks to the Leibniz-Institute for Tropospheric Research (TROPOS) in Leipzig and the Richard-Aßmann-Observatorium (RAO) of the Deutscher Wetterdienst (DWD) in Lindenberg for providing the data for, respectively, LACROS and RAO stations. The authors would like to thank the technical and computer staffs of SIRTA Observatory for taking the observations and making the dataset easily accessible. Comments on early drafts by Christine Knist (DWD) were greatly appreciated. The authors would like to acknowledge all the members of the TOPROF Working Group 3 for providing fruitful discussion on the instrument performances and $\mathrm{O}-\mathrm{B}$ analysis.

Edited by: Marcos Portabella

Reviewed by: Maria Cadeddu

\section{References}

Baldauf, M., Seifert, A., Forstner, J., Majewski, D., Raschendorfer, M., and Reinhardt, T.: Operational convective-scale numerical weather prediction with the COSMO model: Description and sensitivities, Mon. Weather Rev., 139, 3887-3905, https://doi.org/10.1175/mwr-d-10-05013.1, 2011.

Blumberg, W. G., Turner, D. D., Löhnert, U., and Castleberry, S.: Ground-Based Temperature and Humidity Profiling Using Spectral Infrared and Microwave Observations. Part II: Actual Retrieval Performance in Clear-Sky and Cloudy Conditions, J. Appl. Meteor. Climatol., 54, 2305-2319, https://doi.org/10.1175/JAMC-D-15-0005.1, 2015.

Brousseau, P., Berre, L., Bouttier, F., and Desroziers, G.: Background error covariances for a convective scale data assimilation system: AROME 3D-Var, Q. J. Roy. Meteor. Soc., 137, 409-422, https://doi.org/10.1002/qj.750, 2011.

Brousseau, P., Desroziers, G., Bouttier, F., and Chapnik, B.: A posteriori diagnostics of the impact of observations on the AROMEFrance convective-scale data assimilation system Quart, J. Roy. Meteor. Soc., 140, 982-994, 2014

Bubnová, R., Hello, G., Bénard, P., and Geleyn, J.-F.: Integration of the fully elastic equations cast in the hydrostatic pressure terrain-following in the framework of the ARPEGE/ALADIN NWP system, Mon.
Weather Rev., 123, 515-535, https://doi.org/10.1175/15200493(1995)123<0515:IOTFEE>2.0.CO;2, 1995.

Bühl, J., Seifert, P., Wandinger, U., Baars, H., Kanitz, T., Schmidt, J., Myagkov, A., Engelmann, R., Skupin, A., Heese, B., Klepel, A., Althausen, D., and Ansmann, A.: LACROS: the Leipzig Aerosol and Cloud Remote Observations System, Proc. SPIE 8890, Remote Sensing of Clouds and the Atmosphere XVIII, and Optics in Atmospheric Propagation and Adaptive Systems XVI, 889002, https://doi.org/10.1117/12.203091, 2013.

Bulmer, M. G.: Principles of Statistics, Dover Publications, INC., New York, 1979.

Cadeddu, M. P., Liljegren, J. C., and Turner, D. D.: The Atmospheric radiation measurement (ARM) program network of microwave radiometers: instrumentation, data, and retrievals, Atmos. Meas. Tech., 6, 2359-2372, https://doi.org/10.5194/amt-62359-2013, 2013.

Caumont, O., Cimini, D., Löhnert, U., Alados-Arboledas, L., Bleisch, R., Buffa, F., Ferrario, M. E., Haefele, A., Huet, T., Madonna, F., and Pace, G.: Assimilation of humidity and temperature observations retrieved from ground-based microwave radiometers into a convective-scale NWP model, Q. J. Roy. Meteor. Soc., 2692-2704, https://doi.org/10.1002/qj.2860, 2016.

CESAR observatory: available at: http://www.cesar-observatory. nl/, last access: 1 October 2017.

Cimini, D., Hewison, T. J., Martin, L., Güldner, J., Gaffard, C., and Marzano, F.: Temperature and humidity profile retrievals from groundbased microwave radiometers during TUC, Meteorol. Z., 15, 45-56, 2006.

Cimini D., Caumont, O., Löhnert, U., Alados-Arboledas, L., Bleisch, R., Fernández-Gálvez, J., Huet, T., Ferrario, M. E., Madonna, F., Maier, O., Nasir, F., Pace, G., and Posada, R.: An International Network of Ground-Based Microwave Radiometers for the Assimilation of Temperature and Humidity Profiles into NWP Models, Proceedings of 9th International Symposium on Tropospheric Profiling, ISBN 978-90-815839-4-7, L'Aquila, Italy, 3-7 September, 2012.

Cimini, D., Caumont, O., Löhnert, U., Alados-Arboledas, L., Bleisch, R., Huet, T., Ferrario, M. E., Madonna, F., Haefele, A., Nasir, F., Pace, G., and Posada, R.: A data assimilation experiment of temperature and humidity profiles from an international network of ground-based microwave radiometers, Proc. Microrad 2014, Pasadena, USA, 24-27 March, ISBN: 978-1-47994645-7, 978-1-4799-4644-0/14/\$31.00, 2014.

Courtier, P., Freydier, C., Geleyn, J. F., Rabier, F., and Rochas, M.: The ARPEGE project at Météo-France, in: Proceeding of Seminar on Numerical Methods on Atmospheric Models, 2, 193-231, ECMWF: Reading, UK, 1991.

Collaud Coen, M., Praz, C., Haefele, A., Ruffieux, D., Kaufmann, P., and Calpini, B.: Determination and climatology of the planetary boundary layer height above the Swiss plateau by in situ and remote sensing measurements as well as by the COSMO-2 model, Atmos. Chem. Phys., 14, 13205-13221, https://doi.org/10.5194/acp-14-13205-2014, 2014.

De Angelis, F., Cimini, D., Hocking, J., Martinet, P., and Kneifel, S.: RTTOV-gb - adapting the fast radiative transfer model RTTOV for the assimilation of ground-based microwave radiometer observations, Geosci. Model Dev., 9, 2721-2739, https://doi.org/10.5194/gmd-9-2721-2016, 2016. 
Desroziers, G., Berre, L., Chapnik, B., and Poli, P.: Diagnosis of observation, background and analysis-error statistics in observation space, Q. J. Roy. Meteor. Soc., 131, 3385-3396, https://doi.org/10.1256/qj.05.108, 2005.

Güldner, J., Christoph, A., Engelbart, D., Ferrario, M. E., Heret, C., Löhnert, U., Madonna, F., Ruffieux, D., Wrench, Ch. L., and Zoll, Y.: Towards the comparability of microwave observations: Results from a temporary profile network during the WMO campaign LUAMI in November 2008, in: Proceedings of the 8th International symposium on Trophospheric Profiling, Delft, the Netherlands, 19-23 October 2009, ISBN 978-90-6960-2332, 2009.

Güldner, J.: A model-based approach to adjust microwave observations for operational applications: results of a campaign at $\mathrm{Mu}-$ nich Airport in winter 2011/2012, Atmos. Meas. Tech., 6, 28792891, https://doi.org/10.5194/amt-6-2879-2013, 2013.

Haeffelin, M., Barthès, L., Bock, O., Boitel, C., Bony, S., Bouniol, D., Chepfer, H., Chiriaco, M., Cuesta, J., Delanoë, J., Drobinski, P., Dufresne, J.-L., Flamant, C., Grall, M., Hodzic, A., Hourdin, F., Lapouge, F., Lemaître, Y., Mathieu, A., Morille, Y., Naud, C., Noël, V., O'Hirok, W., Pelon, J., Pietras, C., Protat, A., Romand, B., Scialom, G., and Vautard, R.: SIRTA, a ground-based atmospheric observatory for cloud and aerosol research, Ann. Geophys., 23, 253-275, https://doi.org/10.5194/angeo-23-253-2005, 2005.

Hewison, T.: Profiling Temperature and Humidity by Ground-based Microwave Radiometers, PhD Thesis, The University of Reading - Department of Meteorology, 2006a.

Hewison, T. J., Cimini, D., Martin, L., Gaffard, C., and Nash, J.: Validating clear air absorption model using ground-based microwave radiometers and vice-versa, Meteorol. Z., 15, 27-36, $2006 b$.

Hollingsworth, A., Shaw, D., Lönnberg, P., Illari, L., Arpe, K., and Simmons, A.: Monitoring of Observation and Analysis Quality by a Data Assimilation System, Mon. Weather Rev., 114, 861-879, https://doi.org/10.1175/15200493(1986)114<0861:MOOAAQ>2.0.CO;2, 1986.

Ingleby, B. N.: The statistical structure of forecast errors and its representation in The Met. Office Global 3-D Variational Data Assimilation Scheme, Q. J. Roy. Meteorol. Soc., 127, 209-231, 2001.

Lafore, J. P., Stein, J., Asencio, N., Bougeault, P., Ducrocq, V., Duron, J., Fischer, C., Héreil, P., Mascart, P., Masson, V., Pinty, J. P., Redelsperger, J. L., Richard, E., and Vilà-Guerau de Arellano, J.: The Meso-NH Atmospheric Simulation System. Part I: adiabatic formulation and control simulations, Ann. Geophys., 16, 90-109, https://doi.org/10.1007/s00585-997-0090-6, 1998.

Löhnert, U. and Maier, O.: Operational profiling of temperature using ground-based microwave radiometry at Payerne: prospects and challenges, Atmos. Meas. Tech., 5, 1121-1134, https://doi.org/10.5194/amt-5-1121-2012, 2012.

Löhnert, U., Schween, J. H., Acquistapace, C., Ebell, K., Maahn, M., Barrera-Verdejo, M., Hirsikko, A., Bohn, B., Knaps, A., O'Connor, E., Simmer, C., Wahner, A., and Crewell, S.: JOYCE: Jülich Observatory for Cloud Evolution, B. Am. Meteor. Soc., 96, 1157-1174, https://doi.org/10.1175/BAMS-D-14-00105.1, 2015.

Martinet, P., Dabas, A., Donier, J.-M., Douffet, T., Garrouste, O., and Guillot, R.: 1D-Var Temperature retrievals from Microwave
Radiometer and convective scale Model, Tellus A, 67, 27925, https://doi.org/10.3402/tellusa.v67.27925, 2015.

Maschwitz, G., Löhnert, U., Crewell, S., Rose, T., and Turner, D. D.: Investigation of ground-based microwave radiometer calibration techniques at $530 \mathrm{hPa}$, Atmos. Meas. Tech., 6, 2641-2658, https://doi.org/10.5194/amt-6-2641-2013, 2013.

Matricardi, M., Chevallier, F., and Tjemkes, S.: An improved general fast radiative transfer model for the assimilation of radiance observations, ECMWF Technical Memorandum 345, 2001.

Matricardi, M.: The generation of RTTOV regression coefficients for IASI and AIRS using a new profile training set and a new lineby-line dataset, ECMWF Technical Memorandum 564, 2008.

Meunier, V., Löhnert, U., Kollias, P., and Crewell, S.: Biases caused by the instrument bandwidth and beam width on simulated brightness temperature measurements from scanning microwave radiometers, Atmos. Meas. Tech., 6, 1171-1187, https://doi.org/10.5194/amt-6-1171-2013, 2013.

Neisser, J., Adam, W., Beyrich, F., Leiterer, U., and Steinhagen, H.: Atmospheric boundary layer monitoring at the Meteorological Observatory Lindenberg as a part of the "Lindenberg Column": Facilities and selected results, Meteorol. Z., 11, 241-253, https://doi.org/10.1127/0941-2948/2002/0011-0241, 2002.

National Research Council: Committee on Developing Mesoscale Meteorological Observational Capabilities to Meet Multiple Needs, Observing Weather and Climate from the Ground Up: A Nationwide Network of Networks, ISBN: 978-0-309-129862, 250 pp., 2008.

National Research Council: Committee on Progress and Priorities of U.S. Weather (NRC): Research and Research-to-Operations Activities, When Weather Matters: Science and Service to Meet Critical Societal Needs, ISBN: 978-0-309-15249-5, 198 pp., 2010.

Navas-Guzmán, F., Kämpfer, N., and Haefele, A.: Validation of brightness and physical temperature from two scanning microwave radiometers in the $60 \mathrm{GHz} \mathrm{O}_{2}$ band using radiosonde measurements, Atmos. Meas. Tech., 9, 4587-4600, https://doi.org/10.5194/amt-9-4587-2016, 2016.

RAO: Lindenberg Meteorological Observatory - Richard Assmann Observatory, online: https://www.dwd.de/SharedDocs/ broschueren/EN/press/mo_lindenberg_en.pdf?_blob= publicationFile \&v=3, last access: 1 October 2017.

Rose, T., Crewell, S., Löhnert, U., and Simmer, C.: A network suitable microwave radiometer for operational monitoring of the cloudy atmosphere, Atmos. Res., 75, 183-200, 2005.

Rosenkranz, P. W.: Water Vapour Microwave Continuum Absorption: A Comparison Of Measurements And Models, Radio Sci., 33, 919-928, 1998.

Saunders, R. W., Matricardi, M., and Brunel, P.: An Improved Fast Radiative Transfer Model for Assimilation of Satellite Radiance Observations, Q. J. Roy. Meteor. Soc., 125, 1407-1425, 1999.

Saunders, R.: RTTOV-9 Science and validation report, Doc ID: NWPSAF-MO-TV-020, available at: https://www.nwpsaf.eu/ deliverables/rtm/rttov9_files/rttov9_svr.pdf (last access: 1 October 2017), 2010.

Seity, Y., Brousseau, P., Malardel, S., Hello, G., Benard, P., Bouttier, F., Lac, C., and Masson, V.: The AROME-France convectivescale operational model, Mon. Weather Rev., 139, 976-991, 2010. 
Solheim, F., Godwin, J., Westwater, E., Han, Y., Keihm, S., Marsh, K., and Ware, R.: Radiometric Profiling of Temperature, Water Vapor, and Cloud Liquid Water using Various Inversion Methods, Radio Sci., 33, 393-404, 1998.

Stajner, I., Winslow, N., Rood, R. B., and Pawson, S.: Monitoring of observation errors in the assimilation of satellite ozone data, J. Geophys. Res., 109, D06309, https://doi.org/10.1029/2003JD004118, 2004.

Turner, D. D., Clough, S. A., Liljegren, J. C., Clothiaux, E. E., Cady-Pereira, K. E., and Gaustad, K. L.: Retrieving liquid water path and precipitable water vapor from the Atmospheric Radiation Measurement (ARM) microwave radiometers, IEEE T. Geosci. Remote, 45, 3680-3690, 2007.
Waller, J. A., Ballard, S. P., Dance, S. L., Kelly, G. Nichols, N. K. and Simonin, D.: Diagnosing Horizontal and Inter-Channel Observation Error Correlations for SEVIRI Observations Using Observation-Minus-Background and Observation-Minus-Analysis Statistics, Remote Sens., 8, 581, https://doi.org/10.3390/rs8070581, 2016.

Ware, R., Carpenter, R., Güldner, J., Liljegren, J., Nehrkorn, T., Solheim, F., and Vandenberghe, F.: A multichannel radiometric profiler of temperature, humidity, and cloud liquid, Radio Sci., 38, 8079, https://doi.org/10.1029/2002RS002856, 2003.

Westwater, E. R., Crewell, S., and Mätzler, C.: A review of surfacebased microwave and millimeter-wave radiometric remote sensing of the troposphere, Radio Sci. Bull., 310, 59-80, 2004. 